\title{
CORRELATION BETWEEN VARICEAL HEMORRHAGE AND SMALL, SLIDING, ESOPHAGEAL HIATAL HERNIA
}

\author{
ATSUSHI TOYONAGA \\ Second Department of Internal Medicine, Kurume University \\ School of Medicine, Kurume, 830, Japan
}

Received for publication July 27, 1978

\begin{abstract}
Radiological and statistical studies were made on 98 patients with portal hypertension and 200 controls concerning the correlation between small, sliding, esophageal hiatal hernia (S.E.H.H.) and episode or history of variceal hemorrhage.

The high incidence of S.E.H.H. was encountered in the patients with varices. Higher degrees (2nd. +3 rd.) of S.E.H.H. was highly associated with higher degrees (2nd. $+3 \mathrm{rd}$.) of varices.

In the group of higher degrees of S.E.H.H. with association of higher degrees of varices, hemorrhage was highly encountered.

Many would not agree with the configuration of "first degree herniation of the gastroesophageal vestibule alone", then this group was excluded from the final statistical conclusion although the hemorrhage was significant.

In the group of controls the incidence of S.E.H.H. was significantly lower than in that of portal hypertension.

Based on the present data it is most likely that the S.E.H.H. plays an important role in the development of variceal hemorrhage.

Consequently it is mandatory to make a diagnosis of S.E.H.H. especially in the patients with varices for their treatment and the estimation of prognosis.
\end{abstract}

\section{INTRODUCTION}

Variceal rupture is a major and serious complication in the patients with advanced portal hypertension. The mechanism leading to the onset of variceal hemorrhage remains still obscure (Eckart, Grace and Kantrowitz, 1976). However it is generally accepted that predisposing factors to hemorrhage such as direct irritant to the esophageal mucosa, increased portal venous pressure and reflux esophagitis, especially erosions of the esophageal mucosa contribute to hemorrhage from esophageal varices (Wagenknecht, Noble and Baronofsky, 1953; Palmer, 1957 ; Liebowitz, 1961 ; Ornoff and Thomas, 1963 ; Takatsuki, 1960 ; Arakawa, 1974).

Pathological studies in patients who died of variceal rupture have revealed erosions of the esophageal mucosa in $34 \%$ to $69 \%$ of the cases examined (Wagenknecht, Noble and Baronofsky, 1953 ; Chiles, Baggenstoss and Olsen, 1953; Tangehai and Viratchai, 1972 ; 
Eckardt, Grace and Kantrowitz, 1976).

The present studies were initially started from the base on frequent finding of barium reflux to the esophagus while performing barium swallow study and upper gastrointestinal series in the patients with varices. Then a careful $\mathrm{X}$-ray examination designed by Stein and Finkelstein was employed to demonstrate even small hernias. If reflux esophagitis plays an important role in the rupture of esophageal varices, one would have to assume that regurgitation of gastric juice is a common and important finding in these patients. Sliding hiatal hernia would be a common cause for the reflux. Thus, investigation was carried out to correlate the incidence and the degrees of S.E. $\mathrm{H}$. H. with the degrees of varices and with the occurrence of variceal hemorrhage.

\section{MATERIALS AND METHODS}

Studies were made on 98 patients with portal hypertension associated with varices, seen at the Second Department of Internal Medicine, Kurume University School of Medicine and two other affiliated hospitals from March 1972 to April 1975. They consisted of 77 liver cirrhosis, 16 cirrhosis with hepatoma, 3 idiopatic portal hypertension (so-called Banti's syndrome) and 2 extrahepatic portal thrombosis.

The mean age of the patients was 50.5 , with a range from 22 to 79 years. Barium swallow study and upper gastrointestinal series were performed in all patients without routine endoscopic examination. The patients who had apparent peptic ulcer disease were excluded from the cases studied. The control study included consecutive 200 cases of barium swallow studies and upper gastrointestinal series seen at the Se- cond Department of Kurume University Hospital in 1974. The age in the control group ranged from 16 to 82 with mean of 49. The diagnosis of underlying diseases were confirmed by followings;

Physical examination (hepatic and splenic sizes, ascites, collaterals or edema), Blood chemistry (serum albumin, gamma globulin, Bromsulfalein test, Indocyanine green test, serum cholinesterase and alfa-fetoprotein) and Active procedures (upper gastrointestinal series, liver biopsy, $\mathrm{Au}^{98}$ colloid hepatic scintigram, laparoscopy, celiac angiography and splenoportography).

Idiopathic portal hypertension was diagnosed on the morphological findings by liver biopsy, in addition to the splenomegaly, hypersplenism and venous collaterals. Hepatoma was confirmed by liver biopsy, alfa-fetoprotein. celiac angiography and laparoscopy.

The diagnosis of liver cirrhosis was established by liver biopsy, laparoscopy and blood chemistry.

The classification and X-ray technics for demonstration of hiatal hernias designed by Stein and Finkelstein were adopted in order to demonstrate even small hernias (Steins and Finkelstein, 1960).

Classification of small, sliding, esophageal hiatal hernias (Fig. 1).

(1) First degree : herniation of the gastroesophageal vestibule alone. (2) Second degree : herniation of gastroesophageal vestibule plus approximately 2 to $3 \mathrm{~cm}$. of the cardiac end of the stomach above the diaphram.

(3) Third degree : at least 4 or $5 \mathrm{~cm}$. of the cardiac end above the diaphragm.

Clinical X-ray pictures of S.E.H.H. were shown in Fig. 2-A, $-\mathrm{B}$ and-C, and Fig. 2- $\mathrm{A}^{\prime},-\mathrm{B}^{\prime}$ and $-\mathrm{C}^{\prime}$.

The radiological classification of varices stands on the criteria described by Yasumoto (Yasumoto, 1971) as follows. 
Classification of esophageal varices (Fig. 3).

(1) First degree : varices remain below the mid point between esophagogastric junction (diaphragmatic level) and the second narrowing of the esophagus (aortic arch level). Second degree: varices reach above this mid point, but end below the second narrowing. (3) Third degree : varices reach high up above the second narrowing of the esophagus.

Clinical cases of esophageal varices were shown in Fig. 4.

Classification of gastric varices (Fig. 5).

(1) First degree : engorged and tortuous veins only in the gastric cardia. (2) Second degree : engorged and tortuous veins seen in wider extent than the gastric cardia. (3) Third degree

\section{Norma 1}

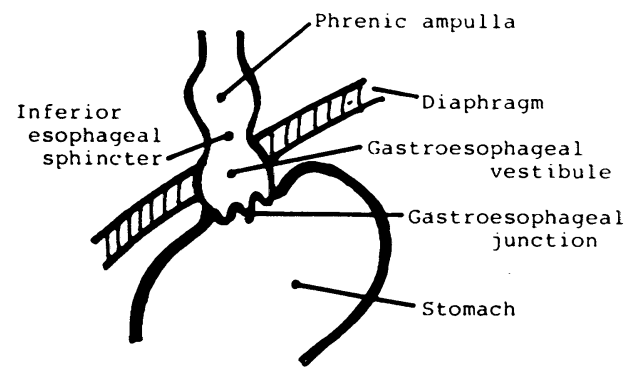

1st.-Degree: The first degree consists of herniations of the gastroesophageal vestibule alone.

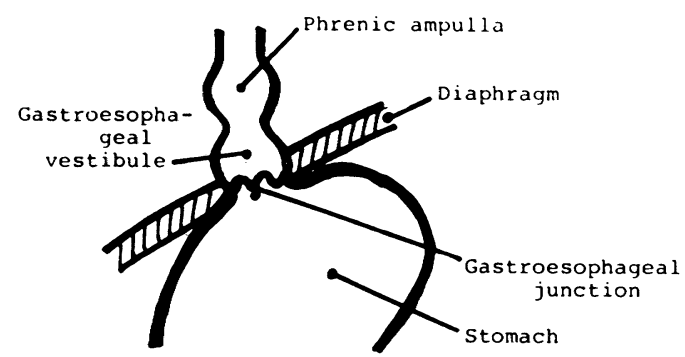

: varicose veins seen as round or tumorous prominences and they are often difficult to discriminate from carcinoma.

Clinical cases of gastric varices were shown in Fig. 6.

\section{RESULTS}

In 98 cases with portal hypertension the incidence of demonstrated esophageal varices was $67.8 \%$ (66 cases), and was lower than that of gastric varices $79.5 \%$ (78 cases). $59.1 \%$ of all cases studied had both esophageal and gastric varices. $7.1 \%$ ( 7 cases) of esophageal varices was not accompanied with gastric varices, whereas $21.4 \%$ (21 cases) of gastric varices was without esophageal ones.
2nd.-Degree: Second degree hernias consist of those of the gastroesophageal vestibule plus approximately 2 to $3 \mathrm{~cm}$ of the cardiac end of the stomach.

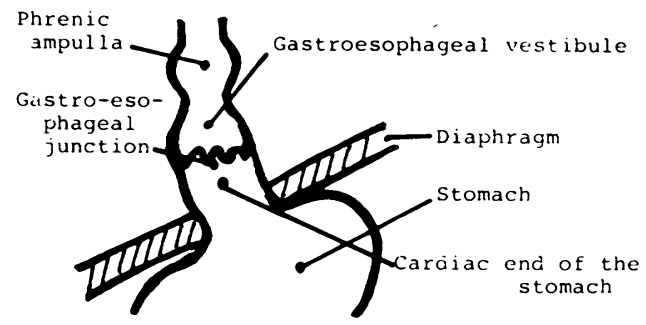

3rd.-Degree: In hernia of the third degree, at least 4 to $5 \mathrm{~cm}$ of the cardiac end of the stomach lie above the diaphragm.

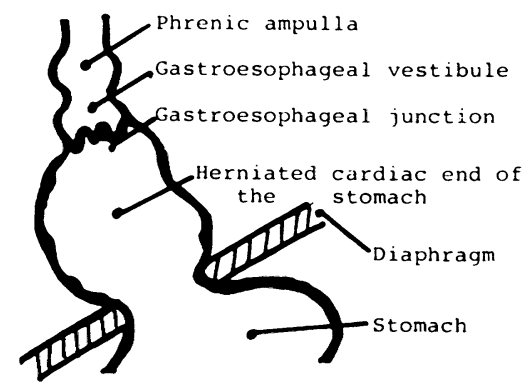

Fig. 1 Classification of small, sliding, esophageal hiatal hernias described by Stein and Finkelstein. 


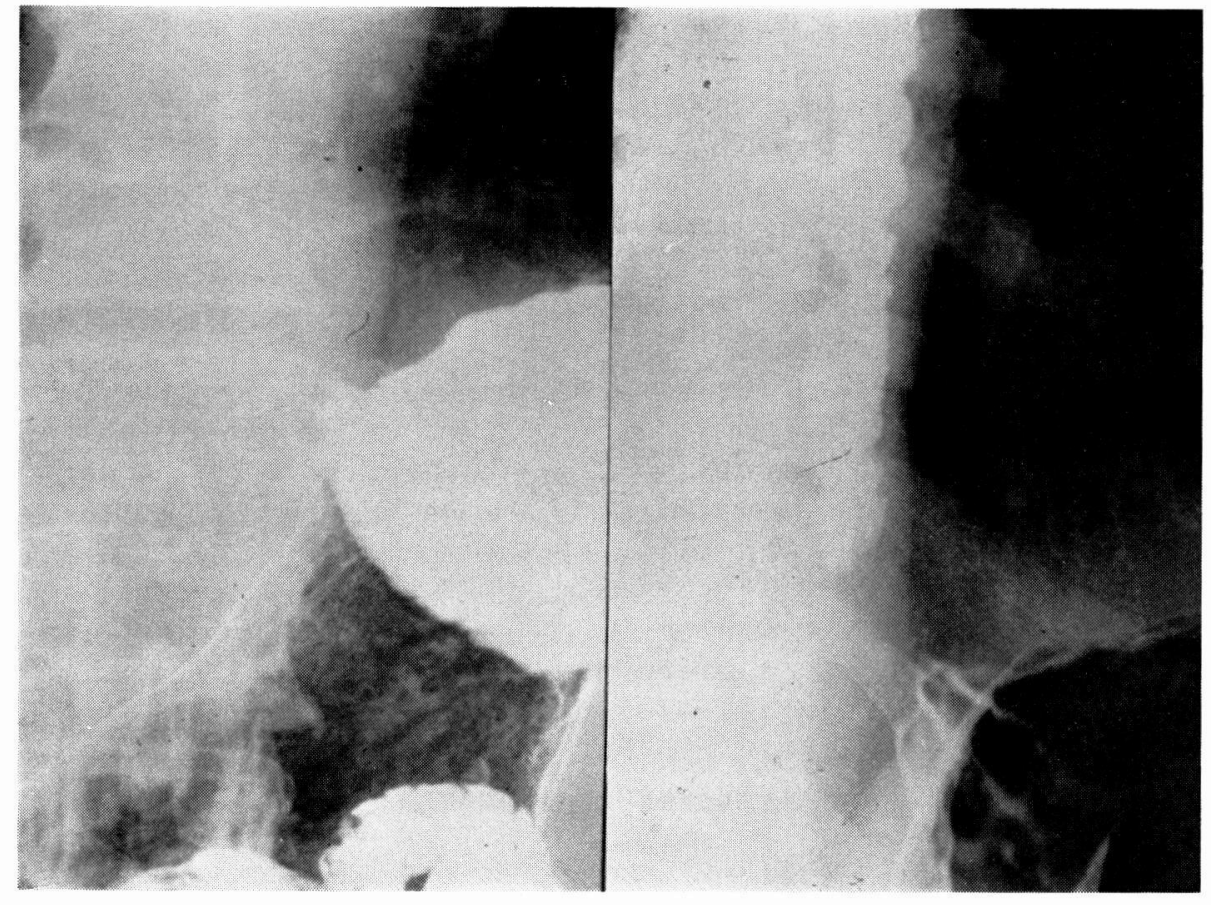

Fig. 2-A First degree of hernia.

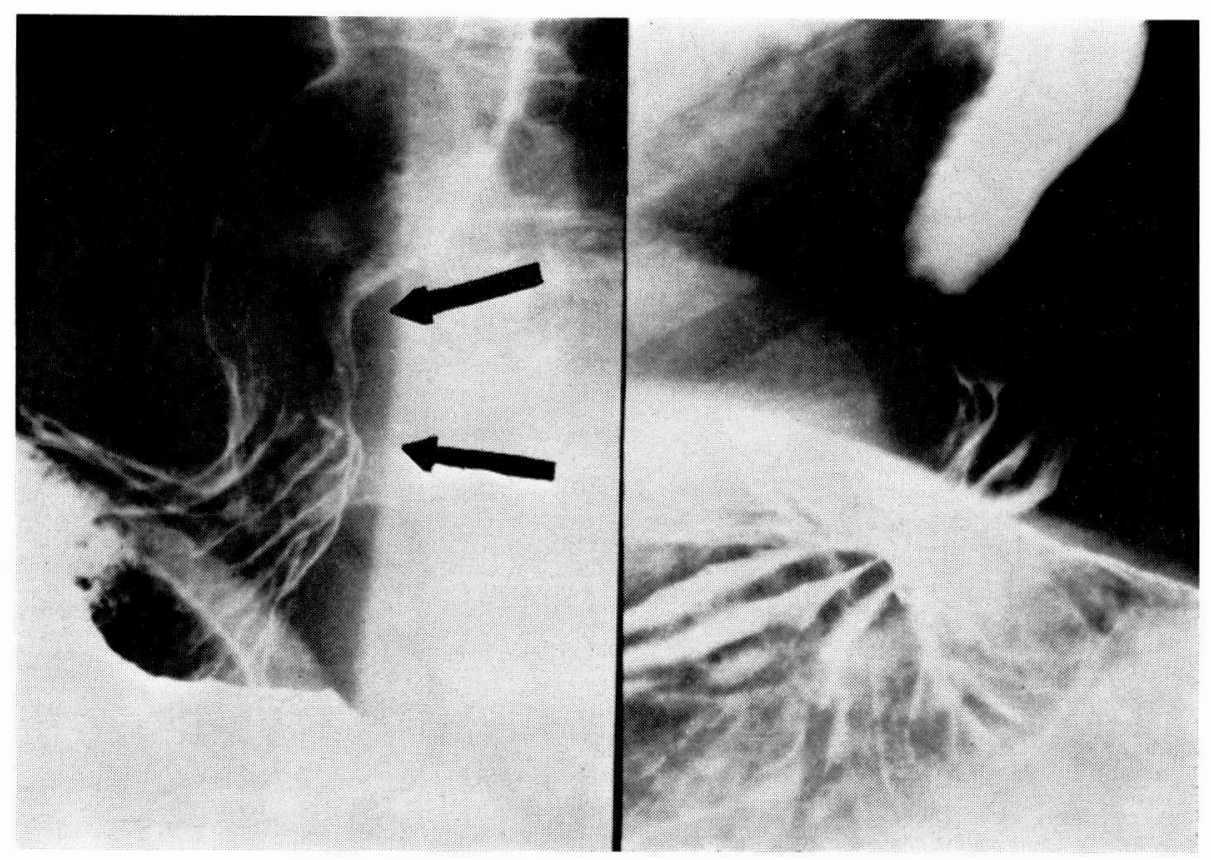

Fig. 2-B Second degree of hernia.

Upper arrow indicates the lower esophageal sphincter. Lower arrow shows the esophago-gastric mucosal junction. 


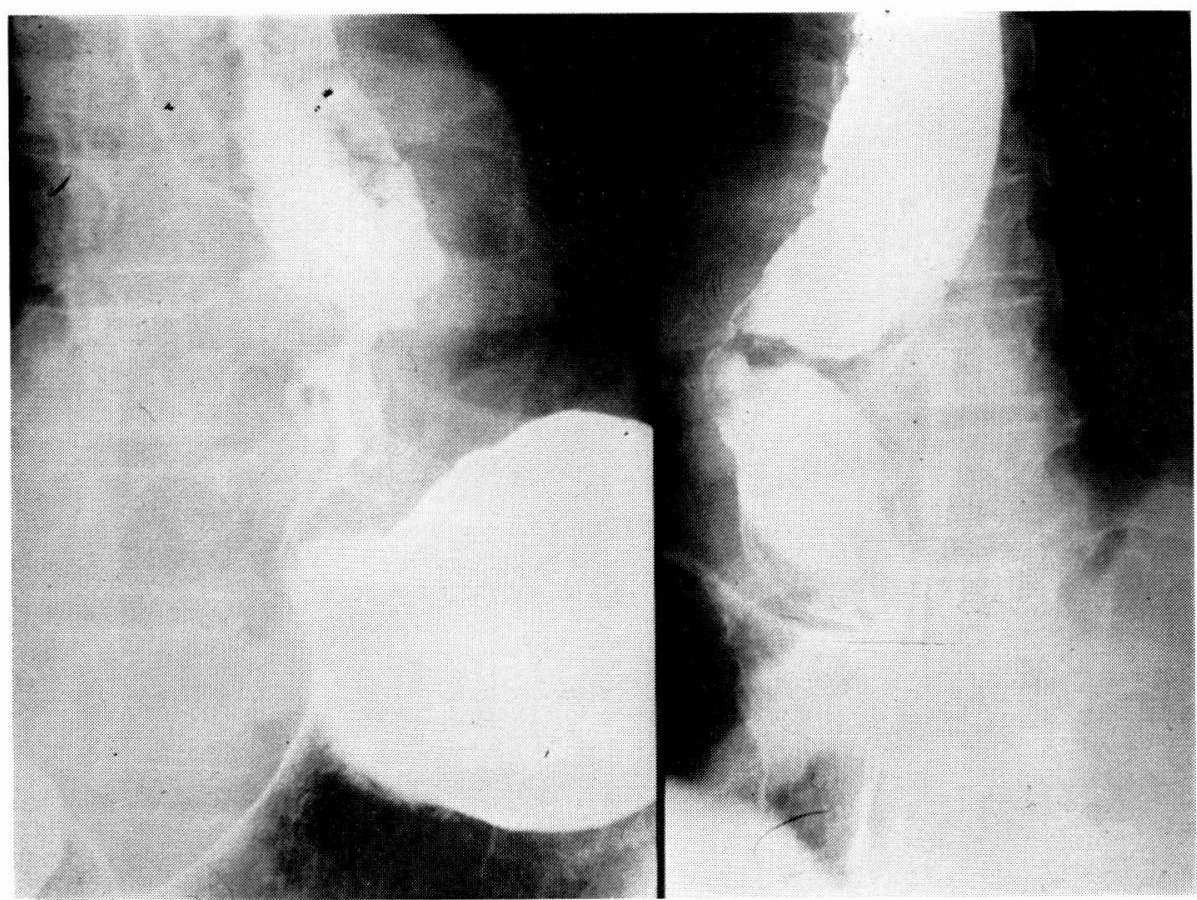

Fig. 2-C Third degree of hernia.

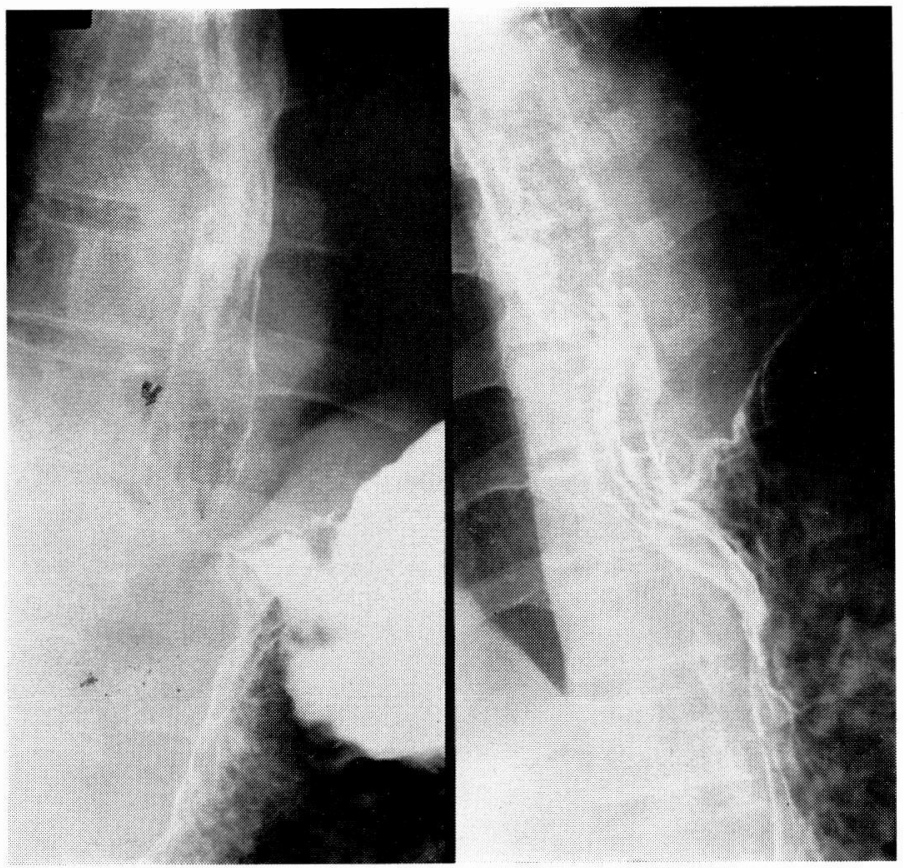

Fig. 2- $A^{\prime}$ 1st. degree of hernia associated with 2nd. degree of esophageal varices. 


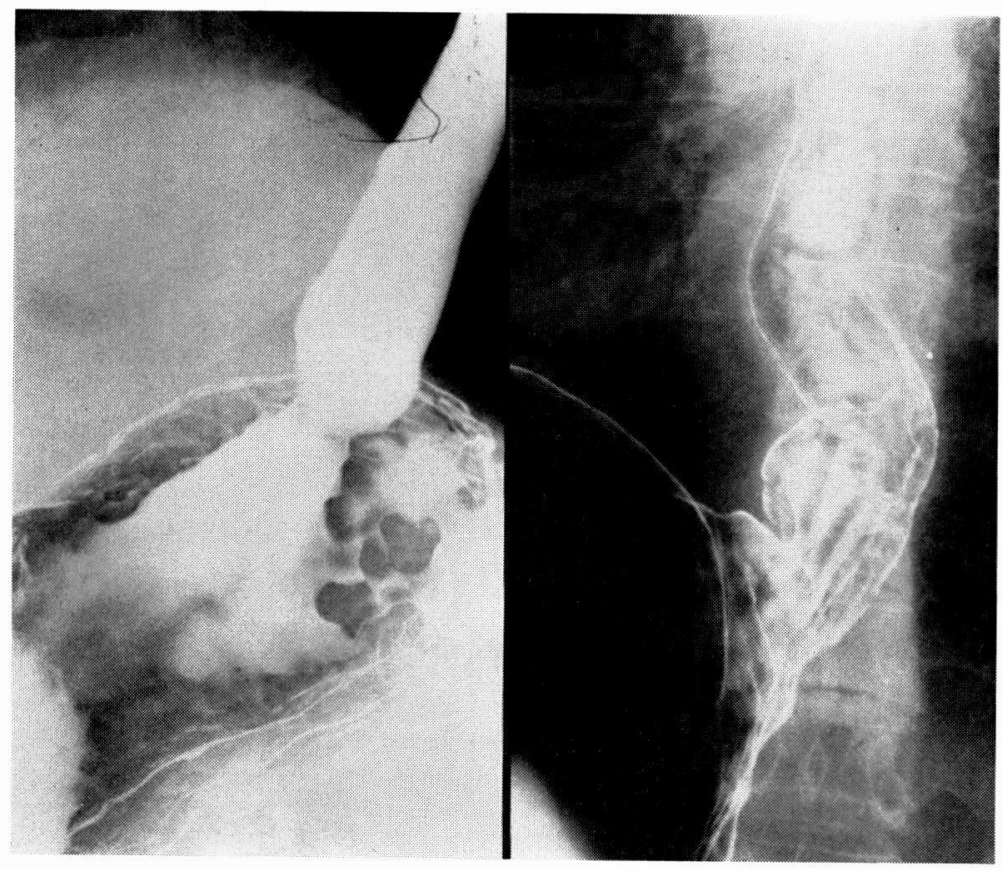

Fig. 2- $B^{\prime}$ 2nd. degree of hernia associated with 2nd. degree of esophageal varices and $3 \mathrm{rd}$. degree of gastric varices.

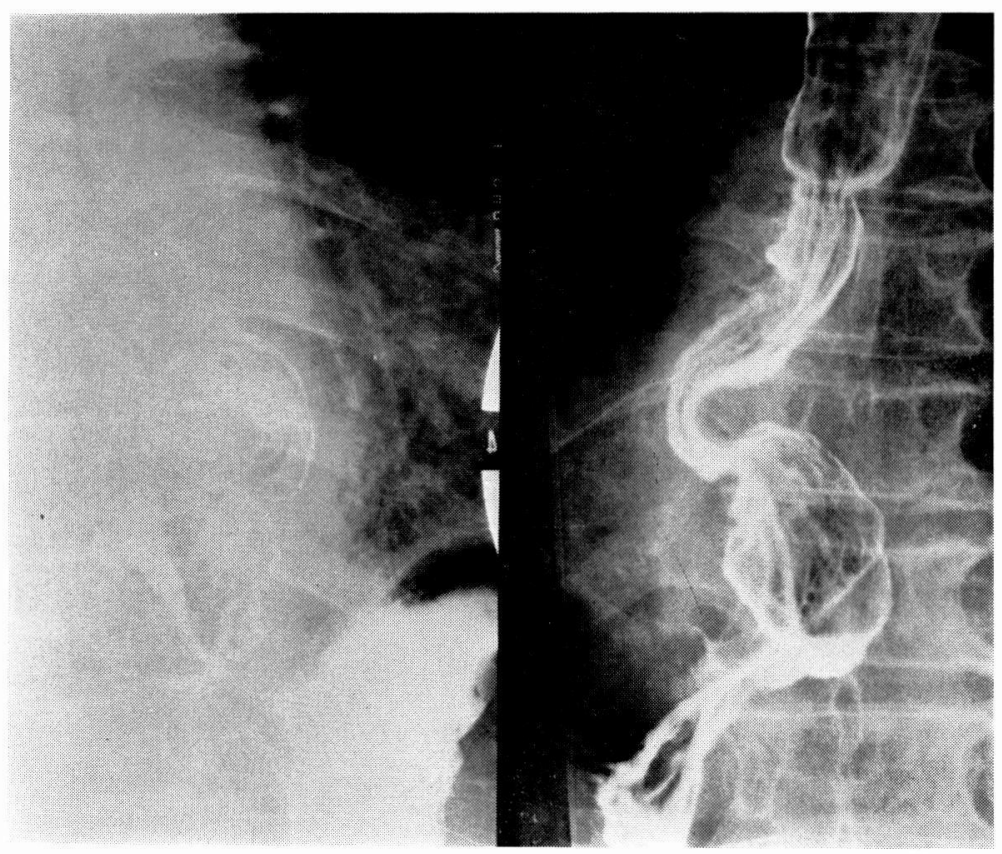

Fig. 2-C' 3rd. degree of hernia associated with 2nd. degree of esophageal varices. 

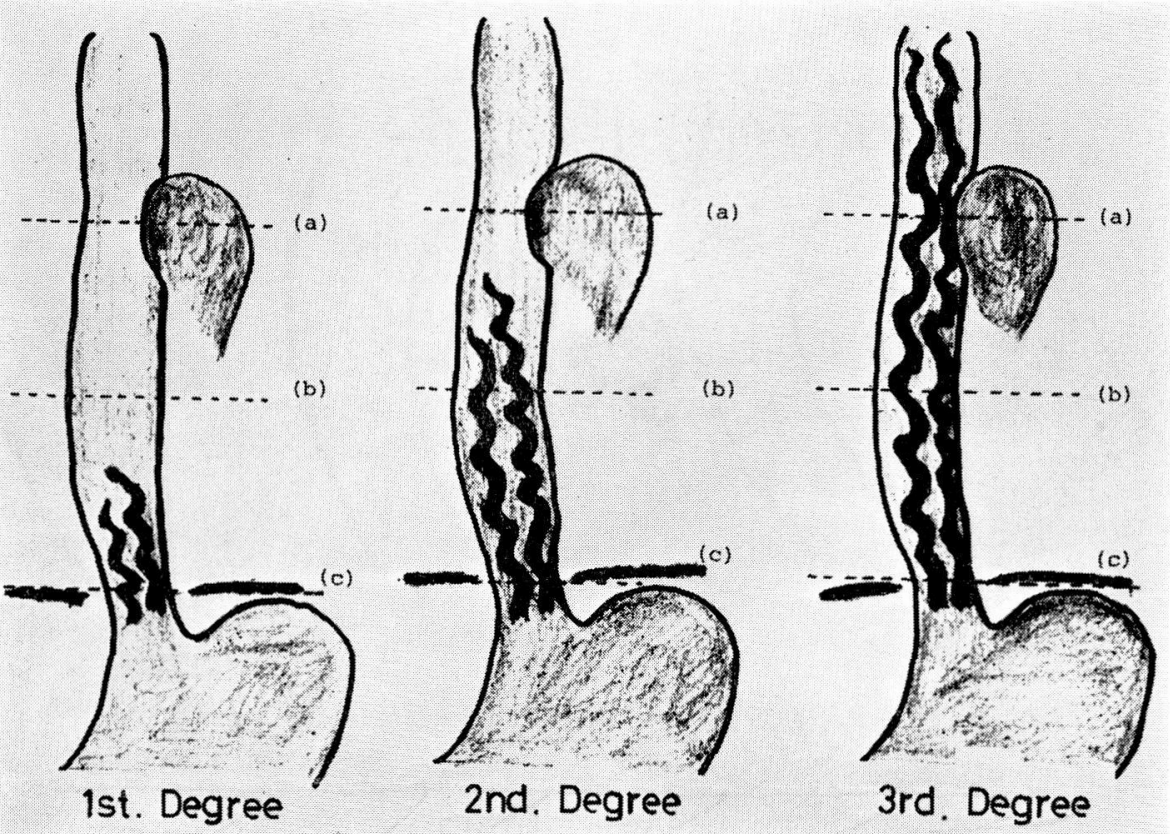

Fig. 3 Classification of esophageal varices described by Yasumoto. (a) The second narrowing of the esophagus (aortic arch level). (b) Mid point between esophagogastric junction and the second narrowing of the esophagus. (c) Gastroesophageal junction (diaphragmatic level).

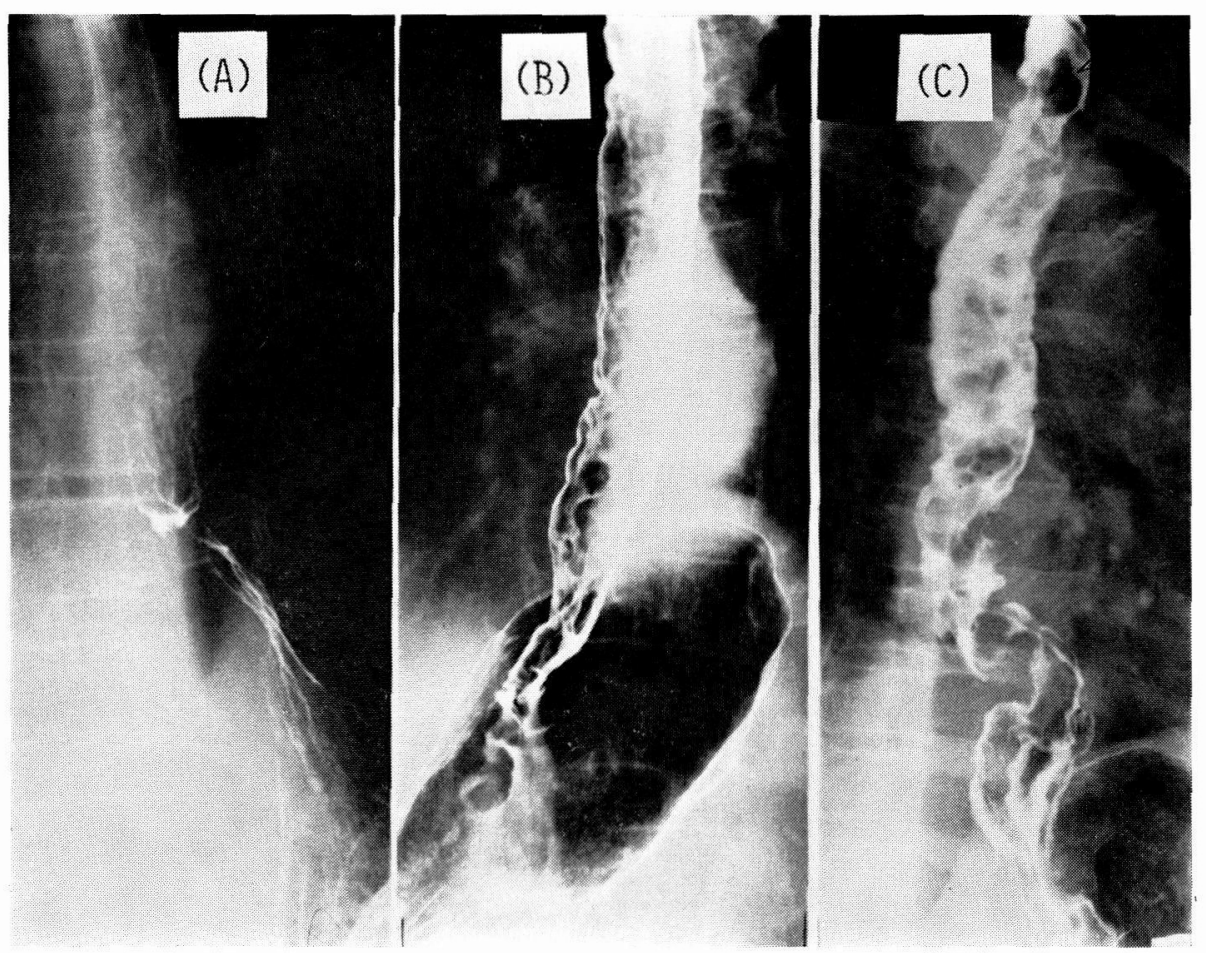

Fig. 4 Esophageal varices; (A) First degree, (B) Second degree, (C) Third degree. Each case is associated with small, sliding, esophageal hiatal hernia. 


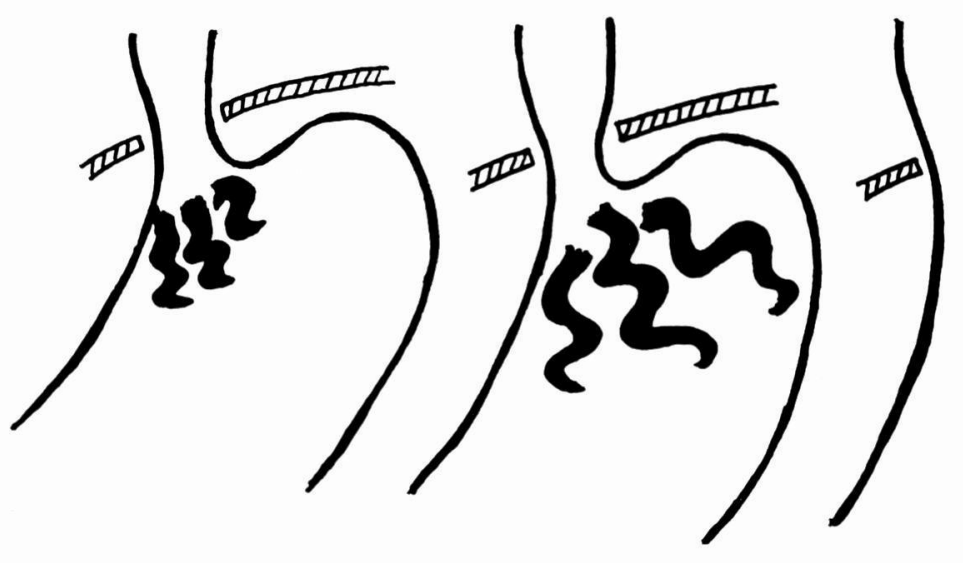

1st. Degree

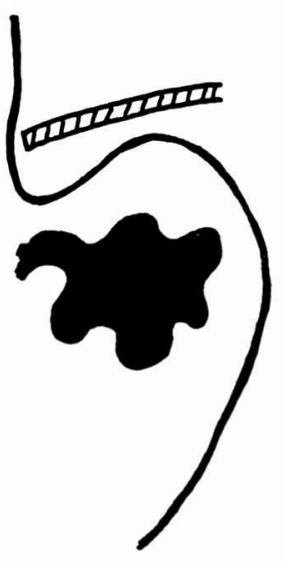

3rd. Degree

Fig. 5 Classification of gastric varices described by Yasumoto.
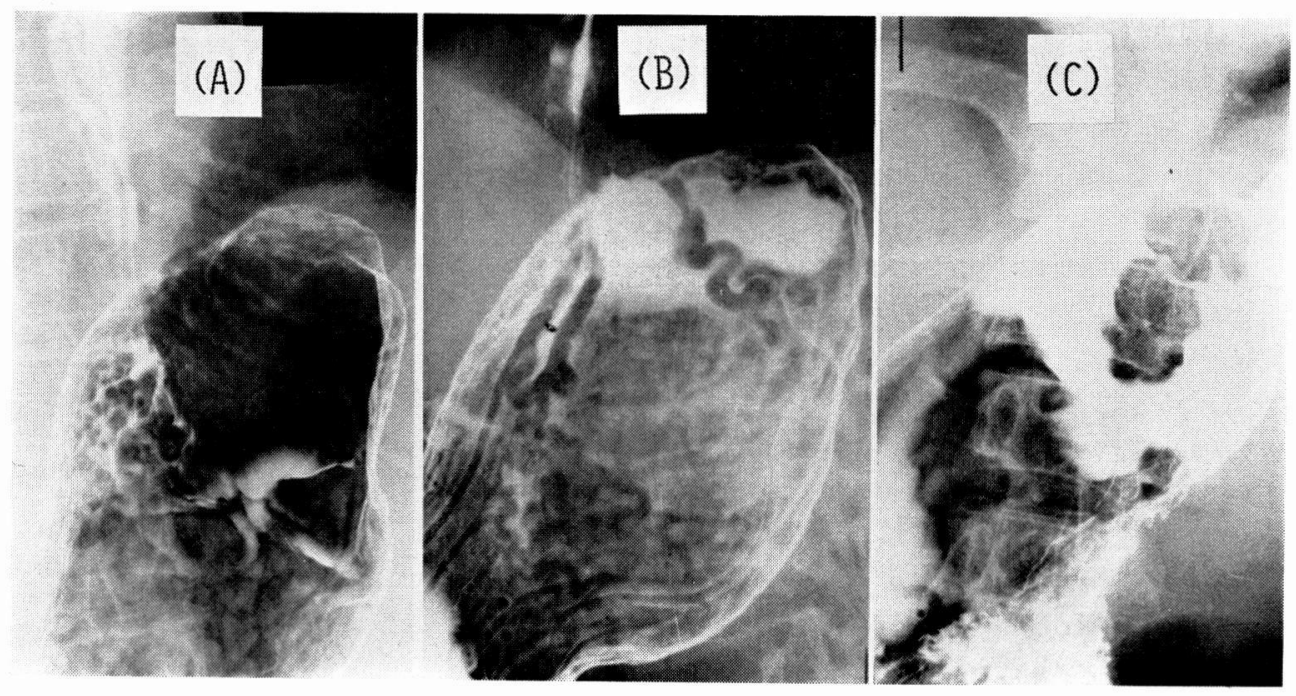

Fig. 6 Gastric varices; (A) First degree, (B) Second degree, (C) Third degree.

TABLE 1

Correlation between Hiatal Hernia and Esophageal Varices

\begin{tabular}{|c|c|c|c|c|c|c|c|c|}
\hline E. V. H.H. & \multicolumn{2}{|c|}{$\begin{array}{l}8 \text { cases } \\
\text { with E.V. - 3rd. }\end{array}$} & \multicolumn{2}{|c|}{$\begin{array}{c}29 \text { cases } \\
\text { with E. V. - 2nd. }\end{array}$} & \multicolumn{2}{|c|}{$\begin{array}{c}29 \text { cases } \\
\text { with E.V. - } 1 \text { st. }\end{array}$} & \multicolumn{2}{|c|}{$\begin{array}{c}32 \text { cases } \\
\text { without E.V. }\end{array}$} \\
\hline $3 r d$. & 1 & \multirow{2}{*}{$50.0 \%$} & 2 & \multirow{2}{*}{$31.0 \%$} & 1 & \multirow{2}{*}{$24.1 \%$} & 1 & \multirow{2}{*}{$21.8 \%$} \\
\hline 2nd. & 3 & & 7 & & 6 & & 6 & \\
\hline 1 st. & 3 & $37.5 \%$ & 15 & $51.7 \%$ & 17 & $58.6 \%$ & 13 & $40.6 \%$ \\
\hline Not present & \multicolumn{2}{|c|}{1} & \multicolumn{2}{|c|}{5} & \multicolumn{2}{|c|}{5} & \multicolumn{2}{|c|}{12} \\
\hline
\end{tabular}

E.V.: Esophageal Varices,

H.H. : Hiatal Hernia 
The S.E.H.H. was detected in $79.6 \%$ (75 cases) of all the patients with portal hypertension studied. On the other hand it was found in $39 \%$ (78 cases) of consecutive 200 controls. Of all cases with portal hypertension and hernias, the third degree was found in $5.2 \%$, second degree $24.5 \%$ and first degree $46.9 \%$. Rest of them $23.4 \%$, was without hernias.
1. Hernias and esophageal varices (Table 1).

In the group of higher degrees (2nd. $+3 \mathrm{rd}$.) of hernias, $50.0 \%$ of cases had third degree of esophageal varices, 31.9 $\%$ second degree and $24.0 \%$ first degree, and $21.8 \%$ had no esophageal varices. The first degree hernias were most frequently seen in the second and first degree esophageal varix cases.

TABLE 2

Correlation between Hernia and Hemorrhage in the Presence of Esophageal Varices

\begin{tabular}{|c|c|c|c|c|c|c|c|c|}
\hline H.H. & \multicolumn{4}{|c|}{23 cases with hemorrhage } & \multicolumn{4}{|c|}{75 cases without hemorrhage } \\
\hline E. V. & \multicolumn{2}{|c|}{19 with E.V. } & \multicolumn{2}{|c|}{4 without E.V. } & \multicolumn{2}{|c|}{46 with E.V. } & \multicolumn{2}{|c|}{29 without E.V. } \\
\hline 3rd. & 2 & \multirow{2}{*}{$52.6 \%$} & 0 & \multirow{2}{*}{$50.0 \%$} & 3 & \multirow{2}{*}{$19.6 \%$} & 1 & \multirow{2}{*}{$20.7 \%$} \\
\hline 2nd. & 8 & & 2 & & 7 & & 5 & \\
\hline 1st. & 6 & $31.6 \%$ & 1 & $25.0 \%$ & 30 & $65.2 \%$ & 11 & $37.9 \%$ \\
\hline Not present & \multicolumn{2}{|c|}{3} & \multicolumn{2}{|c|}{1} & \multicolumn{2}{|c|}{7} & \multicolumn{2}{|c|}{12} \\
\hline
\end{tabular}

H.H. : Hiatal Hernia,

E.V.: Esophageal Varices

2. Hernias and hemorrhage in the presence of esophageal varices (Table 2).

98 cases were placed into two groups of 23 with hemorrhage and 75 without hemorrhage, and the degrees of hernias were detected for comparative studies between both groups. $52.6 \%(\mathrm{p}<0.05)$ of hemorrhagic cases had higher degrees ( $2 \mathrm{nd} .+3 \mathrm{rd}$.) of hernias while only $19.7 \%$ of the nonhemorrhagic cases had them. This difference is statistically significant for the occurrence of hernias.

TABLE 3

Correlation between Hiatal Hernia and Gastric Varices

\begin{tabular}{c|c|c|c|c|c|c|c|c}
\hline G.V. H.H. & \multicolumn{2}{|c|}{$\begin{array}{c}6 \text { cases } \\
\text { with G.V.-3rd. }\end{array}$} & \multicolumn{2}{c|}{$\begin{array}{c}18 \text { cases } \\
\text { with G.V.-2nd. }\end{array}$} & \multicolumn{2}{c|}{$\begin{array}{c}54 \text { cases } \\
\text { with G.V.-1st. }\end{array}$} & \multicolumn{2}{|c}{$\begin{array}{c}20 \text { cases } \\
\text { without G.V. }\end{array}$} \\
\hline 3rd. & 0 & $66.7 \%$ & 0 & $33.3 \%$ & 5 & $24.1 \%$ & 0 & $20.0 \%$ \\
\hline 2nd. & 4 & & 6 & & 8 & & 4 & \\
\hline \hline 1st. & 1 & $16.7 \%$ & 9 & $50.0 \%$ & 31 & $57.4 \%$ & 7 & $35.0 \%$ \\
\hline Not present & \multicolumn{2}{|c|}{1} & \multicolumn{2}{|c|}{3} & & 10 & & 9 \\
\hline
\end{tabular}

H.H.: Hiatal Hernia,

G.V.: Gastric Varices 
3. Hernias and gastric varices (Table 3). In the group of higher degrees of hernias, $66.7 \%$ of cases had third degree of gastric varices, $33.3 \%$ second degree and $23.7 \%$ first degree, and 20.0 $\%$ had no gastric varices. There is a tendency that higher degrees of hernias are associated with higher degrees of gastric varices. In the group of first degree of hernia, second and first degrees of gastric varices were most frequently seen.

TABLE 4

Correlation between Hernia and Hemorrhage in thePresence of Gastric Varices

\begin{tabular}{c|c|c|c|c|c|c|c|c}
\hline \multirow{2}{*}{ H.H. } & \multicolumn{3}{|c|}{23 cases with hemorrhage } & \multicolumn{3}{c}{75 cases without hemorrhage } \\
\cline { 2 - 8 } G.V. & 23 with G.V. & \multicolumn{2}{|c|}{ without G.V. } & 55 with G.V. & 20 without G.V. \\
\hline 3rd. & 2 & \multirow{2}{*}{$47.8 \%$} & 0 & $0.0 \%$ & 3 & $21.8 \%$ & 0 & $20.0 \%$ \\
\hline 2nd. & 9 & & 0 & & 9 & & 4 & \\
\hline 1st. & 9 & $39.1 \%$ & 0 & $0.0 \%$ & 32 & $58.2 \%$ & 7 & $35.0 \%$ \\
\hline Not present & \multicolumn{2}{|c|}{3} & \multicolumn{2}{|c|}{0} & \multicolumn{2}{|c|}{11} & 9 \\
\hline
\end{tabular}

H.H.: Hiatal Hernia,

G.V.: Gastric Varices

4. Hernias and hemorrhage in the presence of gastric varices (Table 4).

Of 23 cases with hemorrhage, $47.8 \%$ (11 cases) had higher degrees of her- nias in association with gastric varices. In nonhemorrhagic cases with gastric varices, only $21.9 \%$ showed higher degrees of hernias. $31.9 \%$ (9 cases) of

TABLE 5

Hiatal Hernia and Splenomegaly

\begin{tabular}{c|c|c|c}
$\begin{array}{c}\text { Spleno- } \\
\text { megaly }\end{array}$ & $\begin{array}{c}\text { More than } \\
\text { 3 T.F.B. }\end{array}$ & $\begin{array}{r}1 \sim 3 \\
\text { T.F.B. }\end{array}$ & $\begin{array}{c}\text { Less than } \\
\text { T.F.B. }\end{array}$ \\
\hline H.H. & 0 & 2 & 3 \\
2nd. & 1 & 6 & 15 \\
1st. & 6 & 15 & 27 \\
Not present & 1 & 8 & 14 \\
\hline
\end{tabular}

Hiatal Hermia and Ascites

\begin{tabular}{c|r|r}
\hline Ascites & $(+)$ & $(-)$ \\
H.H. & 4 & 1 \\
3rd. & 10 & 12 \\
2nd. & 25 & 23 \\
1st. & 14 & 9 \\
Not present & & \\
\hline
\end{tabular}

Hiatal Hernia and Hepatomegaly

\begin{tabular}{c|c|c|c}
$\begin{array}{r}\text { Hepato- } \\
\text { megaly }\end{array}$ & $\begin{array}{c}\text { More than } \\
\text { 3 T.F.B. }\end{array}$ & $\begin{array}{r}1 \sim 3 \\
\text { T.F.B. }\end{array}$ & 1 T.F.B. \\
H.H. & 2 & 2 & 1 \\
3rd. & 9 & 5 & 8 \\
2nd. & 16 & 16 & 16 \\
1st. & 13 & 3 & 7 \\
Not present & &
\end{tabular}

H.H. : Hiatal Hernia

T.F.B.: Transverse Finger Breath 
hemorrhagic cases with gastric varices had first degree of hernia. The remaining three (17.1\%) were without hernias. It suggests that the variceal hemorrhage tends to be associated with higher degrees of hernias in the presence of gastric varices.

The relationship between the S.E. H. H. and splenomegaly, hepatomegary or ascites was not clear as shown in Table 5. However, there was noted that these were often associated with lower degree of S.E.H.H. .

\section{DISCUSSION}

The clinical importance of small, sliding, esophagogastric herniation in variceal hemorrhage has not yet been sufficiently recognized at present along with the difficulty in its diagnosis (Bernard, 1960). In addition to the prefixed concept that not all S.E.H.H. are pathological, the fact that most of them remains asymptomatic has been accounted for such status. Nevertheless, many would agree with a conception that erosions due to peptic esophagitis might be an important factor in the pathogenesis of variceal rupture.

Tissue derangement at the gastroesophageal junctional area due to the presence of varices might account for the occurrence of small, sliding, esophageal hiatal hernias. Fleischer (1956) stated "A small hiatal hernia is frequently a physiological borderline situation without clinical significance, it may, however, have the inherent potentiality of becoming significant."

Stein and Finkelstein (1960) were interested in small hiatal hernia because they were associated with an incidence of gastric juice regurgitation much higher than is otherwise encountered. According to the report by Ishigami and Furuke (1968), increased portal venous pressure and erosions caused by acid-pepsin reflux esophagitis are much accounted of factors for variceal hemorrhage. Takatsuki (1959) observed that resistance of esophageal mucosa against acid-pepsin damage is $1 / 47.5$ of gastric mucosa, which should be interpreted that esophageal mucosa would be easily damaged by gastric content regurgitation. When no hiatal hernia is present, regurgitation of gastric content into the esophagus occurs infrequently.

Such regurgitation occurs even in condition of hiatal insufficiency. Therefore it is felt that the presence of varices makes the esophageal hiatus loose predisposing to the occurrence of S. E. H. H. .

It is generally agreed that normally a supporting and costricting mechanism of the esophagogastric junctional area include diaphragmatic pinch cock, mucosal flap (Hiss-angle), subhiatal fat ring, phrenoesophageal membrane, lower esophageal sphincter and so forth.

When the esophageal and/or gastric varices are found by radiological examination, it is reasonable to consider that the varices are also present in the tissues around the esophagus, and also in the serosal aspect of the stomach. The high incidence of the S.E.H.H. in varices found by this study might be attributable to careful technics of Xray examinations and arather broad definition of the hiatal hernia. Among 1000 consecutive operations, Harrington (1930) found that the esophageal hiatus was tight in $55 \%$, but that one finger could be inserted in $35 \%$ and that 2 or 3 fingers could be inserted in the remaining $10 \%$. Similar information has been provided by Rios Solans (1953), who reported that in $26 \%$ of 50 consecutive autopsies "the esophageal hiatus was open so that herniation could have easily occurred. "It is the impression that when varices are present not only in esophageal or gastric mucosa, 
but also in the surrounding tissues of the lower esophagus or upper part of the stomach, the preserving mechanism of the esophagogastric junctional area at the esophageal hiatus will be deranged predisposing to the occurrence of small, sliding, esophagogastric herniation.

Based on the present data there is a good correlation between S.E.H.H. and varices in their degrees. Variceal hemorrphage was frequent in the group of high degrees of S.E.H.H. associated with high degrees of esophageal and/or gastric varices. Thus, small, sliding, esophageal hiatal hernias might play an important role in the pathogenesis of variceal hemorrhage.

These might support the hypothesis that the presence of varices causes dysfunction of extrinsic preserving mechanism of the esophagogastric junctional area and of the lower esophageal constricting mechanism as like severe hemorrhoids (Ishigami and Furuke, 1968). The X-ray diagnosis of hiatal hernia is usually of clinical importance only insofar as it can be correlated with the patient's symptoms (Stein and Finkelstein, 1960). However, in the patients who have esophageal and/or gastric varices, it is mandatory to make a diagnosis of even small, sliding, esophagogastric herniation for the treatment and prognosis of the patients with varices, even though they are asymptomatic.

\section{CONCLUSIONS}

(1) There is a good correlation between small, sliding, esophageal hiatal hernias (S.E.H.H.) and varices in their degrees.

(2) The high incidence of S.E.H.H. is encountered in the patients with esophageal and/or gastric varices.

(3) Variceal hemorrhage is frequent in the group of higher degrees of S.E.H.H. associated with higher degrees of varices.

From the data mentioned above it is most likely that the S.E.H.H. is an important factor in the patogenesis of variceal hemorrhage. In addition, the present data might support the hypothesis that the presence of varices causes dysfunction of the esophagogastric junctional area. In the patients with portal hypertension associated with varices, the X-ray diagnosis of S.E.H.H. is especially of clinical importance and it is mandatory to make a diagnosis of even small, sliding, esophagogastric herniations for the treatment and prognosis of the patients with varices.

\section{ACKNOWLEDGEMENTS}

Grateful acknowledgements are made to Prof. K. Tanikawa for his constant interest and guidance and to Dr. M. Yasumoto for much assistance and advise.

Parts of these data were presented at the 6 th. World congress of Gastroenterology, Madrid, Spain, July 1978 and 17th. congress of Japanese Society of Gastroenterology, Nagasaki, Japan, Oct. 1975.

\section{REFERENCES}

Arakaw A, M. (1974). Patho-morphological study of esophageal varices. Liber LXIII, 63, 251. Transactiones Pathologicae Japonicae.

Bernard, S. W. (1960). The definition of a sliding hiatal hernia. A radiologist's point of view. Am. J. Digest. Disease., 5, 2, 168-173.

Chiles, N.H., Baggenstoss, A.H. and Olsen, A.M. (1953). Esophageal varices: Comparative incidence of ulceration and spontaneous rupture as a cause of fatal hemorrhage. Gastroenteroly, 25, 565-573. 
ECKARDT,V.F., GRACE,N.D. and Kantrowitz, P.A. (1976). Does esophageal sphincter incompotency contribute to esophageal variceal bleeding ? Gastrenterology, 71, 2, 185-189.

Fleischer, F. G. (1956). Hiatal hernia, peptic esophagitis, Mallory-Weiss syndrome, hemorrhage and anemia, and marginal esophagogastric ulcer. J.A.M.A.,162, 183.

HARRINGTON, S. W. (1930). Diaphragmatic hernia associated with traumatic gastric erosion and ulcer. Surg. Gynec. and Obst., $51,504$.

Ishigami, K. and Furuke, M. (1968). Pathogenesis of bleeding from esophageal varices with special reference to the obliteration of the closing mechanism of esophagogastric junction. Japanese J. Clini. Med, 26, 4 , 168-177.

Liebowitz, H. R. (1961). Pathogenesis of esophageal varix rupture, J.A.M.A., 175, 874879.

ORLoff, M. J. and Thomas, H.S. (1963). Pathogenesis of esophageal varix rupture. A study based on gross and microscopic examination of the esophagus at the time of bleeding. Arch. Surg., 87, 301-307.
Palmer, E.D. (1957). Portal hypertension and esophageal varices. Clinical Gastroenterology. New York, Paul B. Hoeber Inc.,

Rios, S. G. (1953). Sliding hernias through the esophageal hiatus. Brit. M. J., 1, 1029.

Stein, G. N. and Finkelstein, A. (1960). Hiatal hernia, roentogen incidence and diagnosis. Am. J. Dig. Dise, 5, 2.

TANGChai, P. and Viratchai, C. (1972). Ruptured esophageal varices. Relationship to esophagitis. Amount of ascitic fluid and weight of spleen. J. Med. Assoc. Thai, 55, 520-526.

TAKATSUKI, H. (1959). Experimental studies on the pathogenesis of reflux esophagitis, with special reference to the resistance of esophageal mucosa to peptic or tryptic digestion. Archiv Fur Japanische Chirurgie. 28, 6, 2087-2107.

W AGENKNeCht, T.W. Noble, J.F. and BaraNOFSKY, J. D. (1953). Nature of bleeding in esophageal varices. Surgery, 33, 869-874.

Y ASUMOTO, M. (1971). Clinical observations on 100 cases of gastric varices. Japanese J. Gastroent., 68, 7 . 